\title{
Para ler as ruínas do Antropoceno mineiro: catástrofe-crime e trauma cultural em Mariana
}

\author{
Reading Anthopocene's ruins in Minas Gerais: crime/catastrophe \\ and cultural trauma in Mariana
}

\begin{abstract}
Natanael de Alencar Santos ${ }^{1}$
Natasha Karenina de Sousa Rego ${ }^{2}$
\end{abstract}

\section{Resumo}

O artigo busca fornecer algumas indicações sobre como situar o Brasil no Antropoceno. Pergunta-se: como ler as ruínas do Antropoceno brasileiro a partir de desastres recentes? O objetivo geral é aferir a dimensão traumática do Antropoceno Mineiro a partir da catástrofe-crime de Mariana. Os objetivos específicos são, portanto, delinear os contornos do Antropoceno Mineiro, conectando-os com a teoria do trauma cultural de Alexander (2012) e a dinâmica entre valores e sofrimento em Joas (2013). Investigou-se dois documentos - "Estudo $e$ sistematização dos danos morais individuais e coletivos para processo de indenização/reparação dos atingidos e atingidas pela barragem de rejeitos da Samarco Mineração S.A. (Vale e BHP Billiton) em Mariana-MG" e o livroreportagem “Vozes e silenciamentos em Mariana: crime ou desastre ambiental?”, que foram lidos com as lentes da teoria do trauma cultural, das interpretações do Antropoceno e suas vozes no interior das ciências humanas e de contribuições, especialmente decoloniais, que desconstroem entendimentos hegemônicos sobre a relação sociedade-natureza na modernidade. Propõe-se a indissociabilidade entre Antropoceno e as catástrofes; destaca-se a relevância do trauma cultural como um elemento importante na compreensão dos impactos catastróficos; habilita-se uma

\footnotetext{
${ }^{1}$ Mestre em Sociologia pela Universidade Federal da Paraíba. Membro do GETS - Grupo de Estudos em Estética, Técnica e Sociedade (CNPq e DCS/UFPB).

E-mail: alencar.sts@gmail.com

${ }^{2}$ Mestra em Direito pela Universidade Federal de Santa Catarina. Membro do Núcleo de Pesquisa e Estudo em História, Territorialidades e Movimentos Sociais (UESPI/Floriano) e Grupo de Estudos em Direito, Sociedade e Conflitos (UESPI/Corrente).

E-mail: nkarenina@gmail.com
} 


\section{2 | Dossiê - Natureza e Sociedade no Antropoceno - Superando a Separação?}

"leitura de ruínas" para mensurar impactos em tragédias. A importância desta pesquisa reside em explorar esta camada pouco aferida no dimensionamento das catástrofes tecnológicas contemporâneas. A partir dos documentos, conclui-se que existe um processo ativo em curso para estabelecer a catástrofe-crime de Mariana como um trauma cultural - sobretudo no que diz respeito ao descentramento moral, expansão de sensibilidade e na solidificação do evento na memória pública. Além disso, a análise dos documentos demonstra ser viável a leitura das ruínas do Antropoceno brasileiro a partir da centralidade do trauma cultural.

Palavras-chave: Antropoceno. Catástrofe. Trauma Cultural. Mariana. Ruínas.

\section{Abstract}

The article seeks to provide some indications on how to situate Brazil in the Anthropocene. To achieve this goal, the question raised is: how to read the ruins of the Brazilian Anthropocene stemmed from recent disasters? The main objective is to assess the traumatic dimension of the Anthropocene in Minas Grais, specifically through Mariana's crime/catastrophe analysis. The purpose is, therefore, to delineate the contours of the Anthropocene in Minas Gerais, connecting them with the Alexander's (2012) theory of cultural trauma and the dynamics between values and suffering, as argued by Joas (2013). Two documents were investigated - "Study and systematization of individual and collective moral damages for the indemnity / research process of those affected and affected by the tailings dam of Samarco Mineração SA (Vale and BHP Billiton) in Mariana-MG" and the book-report "Voices and silences in Mariana: crime or environmental disaster? ", which were read through the lens of the theory of cultural trauma, of the interpretations of the Anthropocene within the human sciences and contributions, especially decolonial, that deconstruct hegemonic understandings about the society-nature relationship in modernity. It proposes the inseparability between the Anthropocene and catastrophes; cultural trauma is highlighted as an important element in understanding catastrophic impacts; a "ruin reading" is enabled to measure the impacts of tragedies. The importance of this research lies in exploring this small layer linked to the non-dimensioning of contemporary technological catastrophes. From two documents, it concludes that there is an active process underway to characterize Mariana's crime-catastrophe as a cultural trauma - mainly not that it says it respects moral decency, the expansion of sensitivity and the solidification of 
the event in public memory. In addition, the analysis of two documents shows that they are valid for reading the ruins of the Brazilian Anthropocene from the centrality of cultural trauma.

Key-words: Anthopocene. Catastrophe. Cultural Trauma. Mariana. Ruins.

\section{Introdução}

No contexto de crise ecológica, de solidariedade, política e econômica atuais - os contornos nos inspiram a perceber uma crise que é, portanto, civilizatória (LANDER, 2005) - a questão dos desastres e das catástrofes é generalizada, extensa e potente. A amplitude e intensidade da destruição ambiental causada pelas atividades humanas em diferentes âmbitos atingiram, na interpretação relativamente bem difundida e consolidada de cientistas das ciências naturais, a partir de publicação de Paul Crutzen e Eugene Stoermer em 2000, o status de força geológica e a alteração biosférica antrópica é de tal magnitude que a continuidade da própria espécie humana é posta em dúvida - argumento baseado na radicalização da exploração dos recursos da Terra e no impacto ambiental negativo causado pelo aumento populacional, aumento de pastos, acentuação da urbanização, exaustão de combustíveis fósseis, emissão crescente de gases tóxicos na atmosfera, acidificação dos oceanos, extinção em massa, entre outros fenômenos degradantes. Genericamente, esta é a situação básica de "fim do mundo" (KRENAK, 2019; MENEGAT, 2003) ou de incerteza de futuro que o Antropoceno busca nomear.

Contudo, ao extravasar para o território investigativo das ciências humanas, a abordagem sobre Antropoceno se torna mais complexa, ou ainda, revela limitações explicativas. Complexidades que segundo Rita Segato (2011), partindo de uma crítica à relação homem/natureza e tendo por base uma perspectiva decolonial, envolvem limitações na forma que o mundo moderno se constitui ou pensa a si mesmo, não existindo nele dualidade - como relação de complementaridade - e sim binarismo, em que um suplementa o outro. Na mesma esteira, a racionalidade colonial, moderna, cartesiana é fundada em binarismos dicotômicos: homem/natureza, mente/corpo, civilizados/não civilizados e nas ideias de "raça" e "gênero" como instrumentos de classificação hierárquica e padrões de poder (WALSH, 2013). Epistemologicamente, como já bem estabelecido por Bruno Latour 


\section{4 | Dossiê - Natureza e Sociedade no Antropoceno - Superando a Separação?}

(1994), as fronteiras entre fenômenos da natureza e da cultura/sociedade/política - justamente as bases do dualismo clássico humanista cartesiano - são borradas. Isso inspira entendimentos de que

[...] no Antropoceno, ao contrário, é a natureza que se torna efeito do humano. Por onde vagueie, da estratosfera ao mar profundo, o homem encontra doravante - objetivamente, e não mais apenas como projeção de sua consciência - os efeitos de si próprio, de sua ação e poluição industrial. [...] Mais que nunca somos hoje existencialmente vulneráveis ao que se tornou vulnerável a nós. O Antropoceno é, em suma, a revelação da impotência de nossa potência. (MARQUES, 2015, p. 402)

Em nosso juízo, se nas ciências naturais o Antropoceno nomeia toda uma época geológica, nas ciências humanas é preciso refletir, por exemplo, sobre sua suposta potência de universalidade, visto que esta ideia expressa permanências coloniais e modernas, favorecedora da apreensão de grupos humanos e suas vivências complexas e diversas como se homogêneas fossem (SEGATO, 2011). Uma depuração do conceito (que não inaugura o tipo de preocupação que remete, mas reflete uma intensificação contemporânea delas) precisa ser operacionalizada ao focarmos em manifestações particulares, de escalas regionais, em regiões de países em desenvolvimento, bem como para melhor verificar seus efeitos e consequências, na pretensão de contornarmos uma série de ocultações e apagamentos. Assim, nos habilitamos a propor a questão de como situar o Brasil no interior do Antropoceno - qual seria sua contribuição particular? Ou, mais especificamente, como ler as ruínas do Antropoceno brasileiro a partir de desastres recentes?

Para tal, o objetivo geral é aferir o trauma cultural no Antropoceno Mineiro a partir da catástrofe-crime de Mariana. Os objetivos específicos envolvem funcionalizar o conceito de Antropoceno para situar a relação da catástrofe-crime da cidade de Mariana, em Minas Gerais, no contexto de Antropoceno Mineiro; conectar a teoria do trauma cultural de Jeffrey Alexander (2012) e a dinâmica entre valores e sofrimento em Hans Joas (2013) desencadeada pelo Antropoceno, com foco nas experiências traumáticas, e danos causados pelo desastre tecnológico nos e nas atingidas direta e indiretamente por ele. Investigamos dois documentos, lidos com as lentes da teoria do trauma cultural, das interpretações do Antropoceno e de contribuições decoloniais. Propomos então a indissociabilidade entre Antropoceno e as catástrofes; o trauma cultural como um elemento importante na compreensão do impacto. A discussão habilita a perceber 
a "leitura de ruínas", elemento interessante na mensuração de impactos em tragédias e para pensar pedagogias e resistências.

O primeiro documento analisado, o "Estudo e sistematização dos danos morais individuais e coletivos para processo de indenização/reparação dos atingidos e atingidas pela barragem de rejeitos da Samarco Mineração S.A. (Vale e BHP Billiton) em Mariana-MG” foi realizado pela Associação de Advogados de Trabalhadores Rurais no Estado da Bahia, encomendado pela Caritas Brasileira Regional Minas Gerais e concluído em 20183. São apresentados casos, relatos, produtos de entrevistas individuais, de grupos focais e oficinas temáticas. Os dados foram obtidos a partir de observação direta por 4 meses, em 2017, com base na participação dos autores em reuniões, audiências públicas, oficinas, visitas técnicas de campo, celebrações religiosas, atos públicos, dentre outros momentos em que as pessoas atingidas pela catástrofe tecnológica estiveram presentes, valorizando o relato, a lembrança, as avaliações dos próprios atingidos. O objetivo do estudo foi apresentar o conteúdo da experiência daqueles que vivenciaram a tragédia e, a partir dele, argumentar juridicamente pela dimensão do dano moral coletivo. Na conclusão, o documento apresenta uma sistematização e revisão literária sobre a jurisprudência do dano moral coletivo, recomendando estratégias civis de restituição.

O segundo documento que compõe nosso corpus é o livro-reportagem "Vozes e silenciamentos em Mariana: crime ou desastre ambiental?”, organizado pela Doutora Graça Caldas, realizado no âmbito da disciplina Linguagem: Jornalismo, Ciência e Tecnologia, do Programa de Mestrado em Divulgação Científica e Cultural do Labjor/IEL/Unicamp e lançado em 2017. São sete capítulos de autoria dos alunos da referida disciplina, mestrandos do referido programa, com diferentes enfoques. Priorizamos, na presente análise, os capítulos que são realizados em torno dos relatos dos atingidos direta e indiretamente e os relatos em si, embora existam outros trechos que se remetem ao desastre tecnológico e tentem situá-lo num quadro maior, seja de ênfase econômica, histórica, política ou de análise midiática, contando com contribuições de peritos, dados de notas técnicas e outras fontes -

3 O documento ainda não foi publicado. Ele é resultado de uma construção feita pela Comissão de Atingidos através de sua Assessoria Técnica que idealizou e contratou o estudo levado a cabo pela AATR. A Caritas/MG foi contatada pelos autores e autorizou a utilização do documento para os fins desta pesquisa. 


\section{6 | Dossiê - Natureza e Sociedade no Antropoceno - Superando a Separação?}

nisso também contribuem para o dimensionamento e apreensão do processo de trauma cultural.

Criado em 1995, o Laboratório de Estudos Avançados em Jornalismo (Labjor), da Universidade de Campinas (UNICAMP/SP), desempenha desde 2008 a formação em nível de pós-graduação em Divulgação Científica e Cultural, refletindo, problematizando, produzindo e articulando os terrenos entre jornalismo e academia. $\mathrm{O}$ documento que analisamos é um produto acadêmico que encarna uma das principais missões do referido mestrado, isto é, construir "análises, estudos, pesquisas e intervenções no ambiente de produção de ciência e tecnologia, buscando interligar diferentes conhecimentos e saberes na produção de reflexões críticas sobre os impactos e efeitos do desenvolvimento tecnológico" (UNICAMP, s/a).

Em ambos os documentos, os atingidos - seja direta ou indiretamente rememoram o momento do desastre, remetem a experiências de desespero incomensurável; relatam cenas de fuga e apreensão; explicitam sua impotência e horror diante da avalanche de lama; da surpresa trágica, repleta de incredulidade e tristeza; declaram também sentimentos como humilhação e desamparo; descrevem ações de heroísmo e também falam de redes de solidariedade que encontraram na vizinhança nos dias seguintes e de articulações posteriores; percebem que tiveram seus modos de vida transformados e que dimensões imateriais também foram destruídas.

Visto que nos foi viável o acesso a tais experiências coletivas de intenso sofrimento, buscou-se identificar elementos que caracterizam o evento como um trauma cultural com relevância não apenas local, mas, dado suas dimensões, como representante de um trauma cultural que implica todo o Antropoceno. A importância desta pesquisa reside em explorar esta camada pouco aferida no dimensionamento das vultuosas e frequentes catástrofes tecnológicas contemporâneas, aludindo a um itinerário interpretativo no interior das ciências sociais, bem como em operar uma investigação dessa intersecção particular de escalas entre regiões do Sul Global e os macroprocessos do Antropoceno. 


\section{O prisma do antropoceno}

O objetivo deste item é funcionalizar o conceito de Antropoceno para os objetivos aqui estabelecidos, verificando como ele vem sendo articulado e nuançado no campo das ciências humanas e na filosofia e nos capacitando uma apropriação mais ajustada. Na gana classificatória, termos como Entropoceno, Cthulhuceno, Androceno, Euroceno, Plantationceno, Necroceno são proposições análogas que iluminam diferentes facetas de nossa situação cataclísmica.

Tal variedade coloca algumas questões em evidência, a começar pela pretensão de universalidade: quem compõe o “antropos" do Antropoceno? Ou seja, questiona-se até que ponto o termo oclusa, por exemplo, experiências nãoocidentais - e nisso se baseiam muitas das críticas decoloniais (LANDER, 2005; SEGATO, 2011; WALSH, 2002, 2013), que valorizam um descentramento analítico a partir de outras vivências, experiências, saberes (e outras experiências de sofrimentos) de grupos não hegemônicos, do Sul Global. Nesse sentido, o discurso do (e a experiência no) Antropoceno não deve ser tomado como homogêneo, mas plural.

Isso implica mesclar, na moldura geológica do Antropoceno, diversas problemáticas históricas, sociológicas, políticas, econômicas, culturais, psíquicas, jurídicas, entre outras. Assim, é contraproducente ver mesmo os desastres ambientais como "naturais", uma vez que a sociedade sempre está envolvida e implicada.

Adicionalmente, avalia-se a assimetria de agências: "os oprimidos e condenados" (WALSH, 2013) do mundo podem ser acusados e responsabilizados por perpetrar a exploração sistemática e global da natureza? Ora, é notório que as maiores desvantagens e riscos recaem sobre aqueles com menor poder e capital. $\mathrm{O}$ que implica aferir que, no Antropoceno, a responsabilização pela exaustão das condições de vida é diferencialmente atribuída e as desigualdades do sistema capitalistas se destacam: é o Capitaloceno - cujos efeitos não são inerentes à espécie humana, mas à forma com que a atividade dessa espécie é organizada e impacta o planeta. Para Donna Haraway (2015, p.259 - tradução livre) o capitalismo está imbricado na teia da vida: 


\section{8 | Dossiê - Natureza e Sociedade no Antropoceno - Superando a Separação?}

Qualquer geologista do futuro encontrará sintéticos químicos da DuPont na composição das pedras, encontrará sintéticos químicos de corporações petroquímicas e multinacionais farmacêuticas na hidrosfera. A hidrosfera, litosfera, atmosfera, tudosfera, os múltiplos mundos da terra mostrarão os efeitos de seres humanos industriais".

Portanto, na necessária aferição e atribuição de responsabilidade, temos os grandes atores empresariais, estilos de vida, modelo de economia e de exploração que caracterizam o capitalismo contemporâneo como o grande vetor destrutivo, "sustentado numa ruptura metabólica com a natureza - o que leva à sua inconsciente e irreversível destruição" (MENEGAT, 2019, p.161). Dessa forma, a catástrofe é consubstancial ao Antropoceno:

Numa forma social em que a lei do valor é a própria estruturação da realidade - o eixo em que se articula a intencionalidade e a dinâmica das práticas sociais -, são as implosões das barreiras à permanente expansão e acumulação do capital que se apresentam na história como catástrofes anunciadas. Para os países periféricos, estas catástrofes são onipresentes. (MENEGAT, 2019, p.328)

Conforme definição do Capitaloceno por Moore (2016), o capitalismo é encarado não simplesmente como sistema econômico e social, mas a partir da forma que organiza a natureza, capital e poder como um todo orgânico, que realiza uma "ecologia-mundo" de trabalho, poder e (re)produção, situada e multiespécie; o capitalismo organiza a natureza e as condições de vida a sua imagem e lógicas; põe a natureza para trabalhar a seu serviço; apropria fluxos de trabalho e de energia "de graça" ou "por baixo custo" no qual "muitas espécies - e processos biológicos e geológicos - performam trabalho para o capital que não pode ter seu valor aferido em um sistema que valoriza apenas o trabalho pago" (MOORE, 2016, p. 93).

Essa abordagem reverbera ecos do entendimento da racionalidade da técnica moderna ocidental - tal qual investigado por Heidegger (2002), que afirma que ela se apresenta como desencobrimento da disponibilidade. Em termos mais detidos, o filósofo está referindo-se ao processo pelo qual o homem interpela e provoca a natureza afim de explorar-lhe energia com o objetivo de ser beneficiada e armazenada, com o máximo rendimento o mínimo gasto possíveis. Nessa acepção, a natureza é tida como dispositivo, fundo disponível e também reserva, além de passiva de um projeto matematificação, onde as ciências "encaram a natureza como sistema operativo e calculável de forças" (HEIDEGGER, 2002, p. 24). Essa forma matematificada de relação com o mundo é problemática na medida em que tudo é 
passível de disponibilidade, posse, controle e subordinação. Em contraste com ela, para citar apenas um, temos a biointeração (SANTOS, 2015) - uma forma fundamentalmente diferente de encarar a relação com a natureza - e essa distância sintoniza-se com o que aponta Hui (2017) ao pensar em uma cosmotécnica para explicar como a questão da técnica não é universal, é, ao contrário, permeada, habilitada e constrangida por cosmologias particulares, que vão além da mera funcionalidade ou utilidade - ou seja, que leva a sério as diferentes ontologias em diferentes culturas.

Ao longo do texto continuamos usando o nome "Antropoceno" mas apelamos aos leitores que mantenham a consciência sobre a polissemia e ajustes que precisam ser realizadas e que viabilizam nossa abordagem específica.

\section{$O$ antropoceno mineiro}

Com base no caso de Mariana, objetiva-se situar o Antropoceno Mineiro e refletir sobre como o Brasil, e mais especificamente o estado de Minas Gerais, emerge no contexto do Antropoceno. Para tanto, elegemos como foco de investigação o fenômeno do trauma cultura em Mariana, reivindicando para esse evento um lugar de relevância, pois marca de forma indelével o próprio entendimento do Antropoceno - justamente a partir de suas catástrofes. Assim, é premente, ao colocar em evidências as características históricas e socioecológicas de vulnerabilidades regionais e ressaltar que os discursos do Antropoceno não são universais, apontar que existem desigualdades, hierarquias e assimetrias entre as agências causadoras e entre aqueles mais impactados - existe aí também uma multiplicidade de experiências.

As repercussões danosas do Antropoceno põem em maior desvantagem aqueles com menos capital político e material, o que nos dá oportunidades de refletir sobre desequilíbrios de poder por meio de explicações sociológicas/histórias de suas causas plurais - podemos pensar o caso de Mariana como "fato socioambiental total", seguindo Luiz Marques (2015) quando este apropria-se do conceito de Marcel Mauss, devido a grande quantidade de fenômenos e atores que ele consegue congregar.

É uma análise que lida ainda com histórias assimétricas de colonialismo, desenvolvimento e economia política global. O Antropoceno, nesta perspectiva, 
nasce das estruturas do colonialismo - da exploração do homem e da natureza - e das permanências das colonialidades (SEGATO, 2011; WALSH, 2002, 2013). Ele é, portanto, repleto de silêncios: Dahlia Simangan (2009) lembra Gayatri Spivak e os sujeitos humanos silenciados por estruturas hegemônicas de poder e elementos da natureza sem voz. A autora também remete ao historiador Dipesh Chakrabarty, para quem é preciso identificar o impacto da humanidade na Terra, mas que isso só é possível ser feito de maneira decente se reconhecermos a pluralidade humana e as injustiças no interior dela.

Os países de industrialização recente possuem uma relação conflitante com os imperativos de desenvolvimento econômico (focado em produção e dirigido ao consumo) e a política ambiental. Se, por um lado, são os que mais emitem substâncias nocivas ao meio ambiente, por outro, implementam poucas medidas efetivas para reduzir impactos. Para Dahlia Simangan (2019, p.11) "uma análise póscolonial revela como injustiças históricas nascidas de uma longa história de colonização aumentaram a distância de desenvolvimento e criaram problemas e dilemas econômicos e ambientais em países subdesenvolvidos" - contudo, o passado colonial deles não os exime da responsabilidade (não podemos cair nessa armadilha de perdão). Uma outra ressalva desessencializadora importante que emerge na crítica decolonial é que tampouco

todos humanos estão convidados para espaços discursivos nos quais os desastres são teorizados, onde as respostas são formuladas, nem mesmo os discursos sobre o Antropoceno são desconstruídos (VIGNOLA, 2017).

Na modalidade de reflexão aqui proposta, existe explícita uma continuidade entre a exploração colonial de minérios preciosos dos século XVI e XVII com o neoextrativismo de minérios de ferro dos século XX e XXI, em Minas Gerais e em muitos outros lugares do Sul Global, na medida em que sua fundação e desenvolvimento enquanto território são profundamente atravessados por essa forma de exploração, exportação de recursos naturais e dinâmicas de expulsão de inúmeros povos de suas terras tradicionais. Ou seja, a economia de matriz primárioexportadora intensa foi a característica principal dos primórdios do estado e, em grande medida, segue sendo hoje, com inovações tecnológicas poderosas, com a diferença crucial de que não mais a metrópole colonial, mas as empresas transnacionais representam os atores que mais se beneficiam desse esquema. Tal 
matriz econômica é acompanhada de perto pelo dano socioambiental, reversível ou não.

\begin{abstract}
A economia extrativista deteriora grave e irreversivelmente o meio ambiente. $\mathrm{O}$ estudo da atividade mineradora ou petrolífera ao redor do planeta evidencia inúmeros danos e destruições múltiplas e irreversíveis à Natureza. Além disso, são incontáveis as tragédias humanas e a destruição de potencialidades culturais dos povos. No âmbito econômico, a situação não é melhor. Os países cujas exportações dependem fundamentalmente de recursos minerais ou petrolíferos são economicamente atrasados, e seus problemas ambientais crescem no ritmo em que se expande o extrativismo. (ACOSTA, 2016, p. 61-62)
\end{abstract}

Uma consequência da interação natureza e tecnologia na moldura do neoextrativismo se deu em 5 de novembro de 2015, quando Mariana sofreu o maior desastre tecnológico e ambiental do mundo, dita catrástofe. Uma barragem administrada pela Samarco/SA, cujos principais acionistas são a BH Billiton Brasil e a Vale, rompeu. Segundo relatórios preliminar do IBAMA, de novembro de 2015 , o rompimento da barragem lançou dezenas de toneladas de lama contendo resíduos tóxicos, deixando um rastro de destruição de mais de $800 \mathrm{~km}$, nos estados de Minas Gerais e Espírito Santo. Os rejeitos de mineração de ferro afetaram os corpos hídricos da região (mais 6ookm de corpos hídricos poluídos, e mais de 10 toneladas de espécies de peixes foram assassinadas), bem como ecossistemas marinhos que se comunicavam com os rios. A lama devastou ainda florestas nativas, diminuindo permanentemente a biodiversidade local. Povoados na zona rural foram submersos pela lama, tornando-as inabitáveis: por volta de 700 famílias foram removidas compulsoriamente (AATR, 2018, P. 15). O número oficial de mortos é de duas dezenas. Modos de vida foram comprometidos ou inviabilizados definitivamente. Destruição, extinção, morte e ruínas marcam de forma indelével a história da cidade. Frisa-se que a lama atingiu o rio Doce, para o povo Krenak, Watu,

que sustentou a nossa vida às margens do rio Doce, entre Minas Gerais e o Espírito Santos, numa extensão de seiscentos quilômetros, está todo coberto por um material tóxico que desceu de uma barragem de contenção de resíduos, o que nos deixou órfãos e acompanhando o rio em coma. Faz um ano e meio que esse crime - que não pode ser chamado de acidente atingiu as nossas vidas de maneira radical, nos colocando na real condição de um mundo que acabou. (KRENAK, 2019, p.42)

A catástrofe de Mariana parece reverberar o Necroceno, um outro nome para o Antropoceno. Justin McBrien (2016) pontua que o capitalismo é um banquete de mortos, ele devora a vida: faz desaparecer espécies, linguagens, culturas e pessoas. A extinção repousa no coração do capitalismo. Segundo McBrien, seu motor é 
"tornar extinto" o que vive. Ilustrativamente, nesse uso e existência a partir da morte, basta pensar na utilização de petróleo e carvão como explicita exumação de vida extinta. As catástrofes emergem, nesta perspectiva, como o normal do capitalismo - ele precisa de catástrofes para se desenvolver e ampliar espaço de atuação: o fim do mundo se torna cotidiano.

Contudo, partindo de estudo etnográfico de Leila Dawney (2020) e da interpretação do escritor Junot Diaz (2011), temos que as ruínas das catástrofes do Necroceno, essa dinâmica sinistra que se perpetua por meio da matéria morta e da extinção do que vive, é ativada como objeto de conhecimento, de aprendizado. Em Dawney, a provocação da ruína como lugar de descarte, abandono, desolação, espectros, fragilidade, vazio, com foco agudo na relação dos habitantes com o passado pode ser direcionada para descortinar histórias de colaboração criativa, resiliência, construção de novos modos de vida e de cuidado, justificativas de conexão com o lugar, as motivações para permanência, as estratégias de persistência. Por sua vez, Junot Díaz, ao abordar o terremoto no Haiti em 2011, afirma que catástrofes possuem um aspecto apocalíptico da revelação:

[...] que nos dão a chance de ver aspectos de ver o mundo que nós, enquanto sociedade, buscamos evitar, que escondemos debaixo do véu da negação. [...]. Expõem as estruturas de poder subjacentes, as injustiças, os padrões de corrupção e as desigualdades que sequer são reconhecidas [...] Em outras palavras, desastres não simplesmente acontecem. Eles são sempre tornados possíveis por uma série de -geralmente invisíveis escolhas societais que implicam mais do que apenas aqueles que são soterrados ou se afogam. É por isso que os chamamos de desastres sociais. (DÍAZ, 2011, s/p)

Na crise no Antropoceno, "a Terra e o cosmo são transformados em sistema tecnológicos gigantescos” (HUI, 2017, p. 2). É ilustrativo disso o caso dos parques de mineração, onde grandes máquinas abrem enormes feridas na geografia. Do ponto de vista da técnica, que é um forte componente dessa catástrofe de Mariana, o problema não se resume, contudo ao ponto de vista do maquinários, dos instrumentos tecnológicos, mas remete à natureza da relação que é capaz de engendrar - relação matematificada, tirânica, instrumental, atrelada a imperativos capitalistas de acumulação. Parques industriais, grandes máquinas, softwares inovadores e outros alardeados "milagres da tecnologia de ponta" são empenhados nesses vultuosos projetos neoextrativistas - e trazem consigo a promessa de 
progresso, sem mencionar, entretanto, o potencial destrutivo de catástrofes que os acompanham.

Portanto, a catástrofe em Mariana é expressão emblemática do Antropoceno, em antecedentes e permanências, implicação de responsabilidades, magnitude de danos e consequências econômicas, materiais, socioambientais e também, embora pouco elencado para caracterizar essa nova época geológica, em seu aspecto traumático cultural.

\section{Catástrofe e trauma cultural em Mariana}

Apresentado e situado o Antropoceno no Brasil, de forma sintética e na conexão entre colonialidade e contemporaneidade, nesta seção propomos uma conexão entre a teoria do trauma cultural e a dinâmica de sofrimento desencadeada pelo Antropoceno, tendo como foco as experiências e danos causados pelo desastre tecnológico em Mariana, identificado como catástrofe-crime: um monumento sombrio que expõe questões de classe, gênero, raça, idade, nacionalidade, relações de poder e de acesso a recursos. Assim, alguns grupos estão mais propensos que outros aos danos, à perda e ao sofrimento no contexto e diferentes perigos - ou seja, na sociedade do risco (BECK,1997) este não é distribuído igualmente, é assimétrico e mesmo passível de uma série de manobras. A vulnerabilidade social, em um âmbito político, pode ainda ser um gatilho para questões de justiça e de mobilização coletiva.

Um elemento específico que potencialmente caracteriza as catástrofes é o trauma cultural. Isso porque as catástrofes não são traumáticas por si mesmas, não se trata de uma característica inerente ou intrínseca. Conforme Alexander (2012), o sentido delas é fabricado e mediado simbolicamente, atravessado por estruturas sociais; narrativas precisam ser articuladas, elaboradas; o sofrimento precisa ser representado e tomar lugar forte no interior da identidade de certa coletividade. Sociologicamente, é uma perspectiva baseada no construtivismo social, com foco nos elementos configuracionais.

Para que algum evento seja alçado ao status de trauma cultural, ele passa por um amplo "processo coletivo de interpretação cultural” (ALEXANDER, 2012, p. 3). É preciso que uma série de respostas seja construída narrativamente e que significados sejam fabricados. Transformar o sofrimento individual em trauma 
coletivo é um trabalho cultural que envolve ações como "discursos, rituais, marchas, encontres, peças, filmes, contações de histórias" (idem, p. 4). Dessa forma,

[...] o trauma cultural ocorre quando membros da coletividade sentem que foram sujeitos a eventos horríveis, que deixa marcas profundas em suas consciências, transformando suas identidades fortemente, impregnando memórias para sempre. [...] Ao construir traumas culturais é que os grupos sociais, sociedades nacionais e, às vezes, civilizações inteiras, não só identificam cognitivamente a existência de fontes de sofrimento humano, mas também viabilizam a aferição de responsabilidade por eles. (ALEXANDER, 2012, p. 6 - tradução livre)

Alexander (2012) decompõe o processo de trauma cultural coletivo em cinco etapas - a demanda/injúria fundamental; o grupo de transmissão; a audiência e situação; a classificação cultural; as arenas institucionais - com fins analíticodidáticos, não representando necessariamente uma ordem cronológica. O evento em Mariana/MG pode ser lido com as lentes montadas pelo autor, exercício que realizamos adiante:

\section{Mariana/MG pelas lentes do processo do trauma cultura em Alexander}

A demanda ou injúria fundamental é um quesito crucial da construção do trauma cultural. Em Bento Rodrigues, subdistrito de Mariana, os primeiros atingidos diretos são surpreendidos pelo soterramento das cidades, a devastação ambiental e pelo número de mortos ainda não mensurados (AATR, 2018; CALDAS, 2017) - tudo isso conforma um emblema de terra arrasada, ou, em outras palavras, uma situação de fim do mundo. O objeto imediato da demanda coletiva é a assistência emergencial aos municípios da região e aos atingidos e, o mediato, após o estabelecimento e refinamento de um sentido de responsabilização, passa a ser a reivindicação por sanção à Samarco que envolva penalizações, ressarcimento e outras medidas reparatórias decorrentes dos danos causados pela catástrofe-crime, que tem reflexos jurídicos penais, civis, administrativos, constitucionais, ambientais e internacionais.

Aqueles que vocalizam a demanda ou injúria fundamental são os grupos transmissores, conforme nomeia Alexander (2012). Num primeiro momento é a cidade inteira ou mesmo o estado de Minas que compartilha (e se solidariza com) o sofrimento do soterramento, porém fica nítido quem de fato são aqueles que corporificam o trauma, quem são os principais agentes coletivos do processo de 
trauma, elaborando-o: os moradores da região de Mariana atingidos direta ou indiretamente pela destruição da barragem. O dano ambiental irreversível é igualmente eloquente e conta com a verbalização principalmente de ecologistas, ambientalistas e povos tradicionais.

A terceira etapa envolve a projeção da demanda para uma audiência mais ampla, na qual o grupo de transmissão vale-se de articulações simbólicas e do que o autor chama de "atos de discurso performativos" (ALEXANDER, 2012, p. 16) com o objetivo de convencimento. O trauma de Mariana é projetado amplamente por meio da súbita atenção midiática, como acontece em catástrofes de grande vulto. Inicialmente, uma performatividade do sofrimento está presente nos atingidos em algumas marcas simbólicas, ocasionalmente espetacularizada e estigmatizada pela mídia: o desespero pela situação; a tristeza pela devastação; a angústia da busca por sobreviventes; a desproporcionalidade surpreendente da catástrofe e a pequenez dos atingidos frente a ela.

Há, nesse quesito, um forte componente emocional que depois se torna mais argumentativo, racionalizado - marcado por outra expressividade e outra chave de persuasão, o convencimento da audiência quanto ao trauma - lançando mão de dados quantitativos, qualificação jurídica, contextualização conjuntural e abstração política. No que diz respeito a essa etapa, é esse arranjo que torna tanto os atingidos convencidos de seu próprio trauma coletivo e que permite que a audiência mais ampla também passe a atribuir esse teor traumático ao evento.

Segundo Alexander (2012, p.17),

[...] para a audiência mais ampla tornar-se convencida de que ela, também, tornou-se traumatizada por uma experiência ou evento, o grupo transmissor precisa se engajar em um trabalho bem-sucedido de construção de significado.

A partir disso, o autor propõe quatro dimensões de representação, estabelecidas no enquadramento de uma narrativa do trauma cultural, descrito no processo de classificação cultural: natureza da dor; natureza da vítima; relação da vítima do trauma com a audiência mais ampla; e atribuição de responsabilidade.

A respeito da natureza da dor em Marina, o sofrimento é coletivo, abarca a perda de toda uma cidade e tudo que continha, inclusive algumas vidas. A dimensão é apocalíptica: equivalente a de grandes eventos da natureza como terremoto ou tsunamis - só que de lama tóxica é proveniente de um empreendimento comercial, 
ou seja, a catástrofe tem fontes antrópicas. Toneladas de lama tóxica que engolem todo um território, num rastro de centenas de quilômetros de morte, sujeira, apagamento em uma desigual, assombrosa e que apequena as vítimas. A descrição da dor de Mariana se firma compatível com a noção de "rastro de morte" que põe fim a mundos (KRENAK, 2019; MENEGAT, 2003).

Por vez, quanto à natureza da vítima, atenta-se ao fato de que as pessoas ora atingidas estavam completamente vulneráveis, desavisadas no momento do rompimento da barragem. Havia o potencial de dano, mas ele era amenizado ou invisibilizado pela retórica dos protocolos de "controle técnico" da empresa que seriam capazes de evitá-lo e contê-lo ou que considerava tal acidente tecnológico como uma possibilidade afastada por laudos e autorizações técnicas, conforme indícios apontados no livro organizado pela professora Graça Caldas (2017). Entre os mortos estão os trabalhadores da empresa e moradores da região próxima, em sua maioria trabalhadores rurais, camponeses. Eram pessoas simples numa cidade pacata e relativamente [tornados] indiferentes ao risco.

As vítimas diretas e indiretas possuem sofrimentos e urgências específicos. As primeiras são os mortos, os desabrigados, os removidos, as famílias destes, a floresta destruída, as toneladas de animais mortos; as segundas são, por exemplo, as que tiveram o abastecimento de água interrompido ou prejudicado, a economia pesqueira inviabilizada, as pessoas da região que viram o comércio e a renda diminuir.

Em seu turno, a relação das vítimas do trauma com a audiência mais ampla no caso da catástrofe-crime de Mariana equivale, em certo sentido, a relação que se constrói entre vítimas de grandes tragédias "naturais" (como terremotos, enchentes, furacões) e aqueles indivíduos distantes, e que acompanham o desenrolar do sofrimento - sobretudo pela mídia.

De espectadora, a audiência tem estimulada em sua capacidade de identificação, e torna possível, por exemplo, uma aderência à narrativa que imputa responsabilidade direta à Samarco. Além disso, sensibilizada, passa a ser capaz de protagonizar rupturas na moldura que naturaliza ou dessensibiliza reações às catástrofes-crimes. Aqueles que perderam tudo ou muito - moradia, bens, parentes, amigos, alguns a própria vida - chocam pela situação abrupta de impotência, vulnerabilização, despossessão e de vida depois do fim do mundo. 
A atribuição de responsabilidade é um outro elemento da etapa de classificação cultural. Ela diz respeito à identificação de antagonistas, dos perpetradores da injúria fundamental (ALEXANDER, 2012, p. 19). Em Mariana, pode-se perceber que a construção de uma responsabilização foi alvo de disputas, uma vez que deslizou de uma tragédia ou acidente inevitável para ser enquadrada como crime por negligência, com componentes inclusive de corrupção, uma vez que membros diretores da empresa ignoraram laudos que alertavam para problemas na barragem e continuaram com as atividades (CALDAS, 2017, p. 66). A interpretação que prevalece no primeiro caso é que a empresa figura como vítima quase tanto quanto as pessoas, ela chega a ser humanizada; na interpretação que acompanha a segunda versão, se torna claro como o acidente poderia ter sido evitado - seja o rompimento da barragem, seja a possibilidade de prevenir maiores danos caso fossem obedecidos os protocolos de segurança em situação de rompimento, visto que nem ao menos a sirene de emergência tocou, o que poderia ter poupado mais vidas. Isso implica outro deslizamento: a tragédia passa a ser percebida não apenas pelo viés da caridade ou da ajuda emergencial e filantrópica, mas como um problema maior, como um debate sobre reparação bem como sobre as dimensões e os limites da exploração mineradora.

Por fim, as arenas institucionais são igualmente cruciais na transformação de experiências de sofrimento coletivo em traumas, por meio da criação e fortalecimento de uma “(re) classificação cultural” (ALEXANDER, 2012, p. 19) - sejam elas as arenas religiosa, estética, legal, científica, midiática ou mesmo a burocracia do estado.

No caso da catástrofe-crime de Mariana, a mídia, sobretudo os grandes veículos de comunicação nacional e internacionais, foi uma das primeiras arenas na qual as narrativas do desastre foram apresentadas e diferentes versões entraram em disputa. As catástrofes possuem, nos manuais de comunicação, um valor notícia ímpar (SILVA, 2005), um motivo para veiculá-las com destaque. As imagens de devastação, o sofrimento trágico, o acidente evitável, o crime e a negligência, o heroísmo das equipes de salvamento, a comoção são alguns atributos da cobertura midiática que circularam e ainda circulam hoje, com muito menos frequência.

Movimentos sociais e ambientais também são mobilizados pela própria atenção e atuação em eventos similares como rompimento de barragens. Assim, têm a capacidade de alertar para a complexidade dos danos, em suas dimensões 
socioambientais e ecológicas, por meio de gramática que nomeia os processos vivenciados.

Na esfera legal e burocrátrica de Estado, o Ministério Público Federal (MPF), Ministério Público do Estado do Espírito Santo (MPE/ES), Ministério Público do Estado de Minas Gerais (MPE/MG), Polícia Civil de Minas Gerais (PCMG) e Polícia Federal (PF), cada um em seus trâmites processuais e competências constitucionais, realizaram investigações para apurar o que ocorreu, os porquês e os possíveis responsáveis nas esferas civil, administrativa, penal e ambiental (CALDAS, 2017). Sublinha-se a propositura de ação popular pelo MPF em 2016 contra a Vale, Samarco, BHP Billiton Brasil, União e os Estados de Minas Gerais e do Espírito Santos para que sejam obrigados judicialmente a reparar integralmente os danos (MPF, 2016).

Destaca-se que em audiência, em outubro de 2018, no Tribunal de Justiça do Estado de Minas Gerais (TJ/MG) pactuou-se que a Cáritas Brasileira Regional Minas Gerais ficaria responsável pelo cadastro das famílias atingidas pelo rompimento da barragem de Fundão, em Mariana-MG, com entrega de 900 dossiês entregues em 2018 e mais algumas centenas sendo realizados em 2019 (A SIRENE, 2020). Em fevereiro de 2020, o TJMG negou recursos de Samarco e os atingidos, nas indenizações, poderão exigir a atualização da Matriz de Danos usada como base de cálculo para valores mais próximos aos perdidos (O TEMPO, 2020).

$\mathrm{Na}$ esfera científica, seja por meio das universidades ou órgãos técnicos oficiais ou independentes, estudos foram e vêm sendo realizados para problematizar condicionantes, consequências e construir análises em variadas dimensões. É o caso de um dos documentos que nos serve de fonte, o livro construído na disciplina Linguagem: Jornalismo, Ciência e Tecnologia do Programa de Mestrado em Divulgação Científica e Cultural do Labjor/IEL/Unicamp: "Vozes e silenciamentos em Mariana - crime ou desastre ambiental”, ele exemplifica como opera essa esfera. Este trabalho que você tem em mãos também se insere nesta arena.

Percebe-se que as cinco etapas do processo de trauma cultural coletivo em Alexander (2012) podem ser plenamente ilustradas pela catástrofe-crime em Mariana com base nos documentos analisados, que embora originalmente não mencionem esse conceito ou partam desta interpretação, estão em pleno acordo com essa classificação específica da experiência de sofrimento mineira. 


\section{Leitura de Ruínas}

O trauma cultural é, relembramos, emblema de uma ruptura abrupta que deixa uma marca indelével em certa coletividade. É algo capaz de operar a divisão antes-depois, é fratura, é inflexão que tem facetas psíquicas/emocionais, materiais e imateriais, culturais, simbólicas. Na catástrofe-crime de Mariana operou uma série de alterações dramáticas que passamos a ressaltar com o objetivo de exercitar uma espécie de "leitura de ruínas", do resultado da catástrofe, focando em alguns elementos-chave a partir da análise dos documentos: as feridas à dignidade, os danos imateriais e existenciais; a reconfiguração forçosa de identidades; o drama da visibilidade/invisibilidade; a desterritorialização; e a destruição ecológica.

O estudo elaborado pela AATR/BA exercita uma categorização do dano moral (individual e sobretudo coletivo). É premente notar as estratégias de aferição empenhadas pelo grupo de trabalho: partem de dados coletados em campo, prioritariamente relatos diretos, e realizam uma revisão na literatura jurídica nacional e internacional. Nesse sentido, o dano moral é apresentado tanto como uma ferida à dignidade - inerente aos sujeitos enquanto direitos humanos e fundamento constitucional - em sentido individual como em sentido coletivo - que passa inclusive pelo direito ao meio ambiente sadio - quanto uma violação a bens não-materiais que integram o âmbito dos direitos da personalidade.

A definição de trauma coletivo de Alexander remete-se diretamente a uma reconfiguração da identidade. Eventos de natureza geográfica como o soterramento de lama tóxica, consequência do extrativismo neocolonial selvagem, danificaram as identidades dos moradores da região, que passaram a ser definidos, após a catrástrofe-crime, como "atingidos". As diferentes nuances das identidades que envolve diferentes formas de agir, pensar, relacionar-se, identificar-se e diferenciar-se - tornaram-se achatadas por essa denominação, ainda que posteriormente ela tenha sido funcionalizada estrategicamente, como acontece com movimentos sociais, a exemplo do Movimento dos Atingidos por Barragens. Os relatos disponíveis nos documentos apontam ainda para um processo de estigma (GOFFMAN, 2008), no qual os atingidos são apregoados como "barrentos" (AATR, 2018, p. 37), inferiorizados e discriminados. Essa nomeação opera ainda uma imputação de responsabilidade moral pelo ocorrido, tendo em vista que a atividade econômica mineradora da região foi suspensa em decorrência das decisões judiciais 
que envolvem, mas não apenas, a situação dos moradores atingidos direta ou indiretamente. Tal interrupção gerou descontentamento de parcela da população que chegou a engajar-se em passeatas reivindicando o retorno da Samarco - e desencadeou o processo de estigma.

Um desdobramento da dimensão identitária é o das vincularidades dos atingidos (a vizinhança, as parcerias de jogar bola e tomar banho no rio, por exemplo). Relações cotidianas que os sujeitos travavam naquela região que foram de uma hora para outra evaporadas. Existe um aspecto forte aqui que remete ao território como um elemento do sentimento de pertença, o palco/cenário concreto/físico onde se desenrolava associações. Há ainda uma fratura não apenas nas expressões objetivas de garantir e continuar a vida objetiva, econômica, mas também no tocante a memória coletiva.

A tragédia-crime evidenciou a magnitude da assimetria de poder entre mineradoras e comunidades - e a ampla potência da capacidade do setor minerador de causa danos materiais e imateriais e a impotência dos atingidos. É um debate que remete às vulnerabilidades e vulnerabilizações, sobre como elas foram tratadas, sobretudo, após a tragédia-crime - seja no sentido de tentar dirimi-las ou de mantê-las fora da moldura de discussão. Nesse sentido, uma das abordagens centrais do livro elaborado pela turma de mestrandos do LABJOR Unicamp traz é o drama da visibilidade/invisibilidade: série de apagamentos (ou soterramentos) que são efetivados tanto pela grande mídia tradicional, quando pelas disputas políticas em curso.

Uma ênfase importante desse trauma coletivo é a relação com o meio ambiente (os entes não-humanos - fauna e flora, recursos hídricos, etc - não apenas para uso, mas como lazer, deleite ou preservação intrínseca) ou, dito de outra forma, o escopo do dano ecológico/ambiental. É importante destacar que para algumas populações tradicionais atingidas, como o povo indígena Krenak, o dano ambiental permeia a própria dignidade e existência de meus membros - ou seja, a fronteira entre cultura e natureza não se apresenta. Então os atingidos, além de serem vários e múltiplos, são atingidos de maneiras diferentes - em sua cosmologia, em seus entes sagrados, seus rituais, suas formas de conexão com o mundo (alimentação, práticas).

Todos esses elementos confluem para a sombria pedagogia da leitura de ruínas, com a qual nos posicionamos de forma a aprender com o sofrimento. Uma 
dimensão parece ser, adicionalmente, relevante para que esse aprendizado seja viabilizado. Para que o trauma cultural de Mariana seja projetado como uma acusação das tendências destrutivas consubstanciais de todo o Antropoceno (cujo enunciado é eivado pelo sentido de Capitaloceno e de Necroceno) ele precisa contar com outros "denunciantes" além dos atingidos, como discutido acima. Dito de outra forma, é importante perceber no caso analisado nesta pesquisa um processo de deslizamento específico da mobilização de ajuda humanitária emergencial nos primeiros momentos após a tragédia-crime para uma leitura politizada das implicações do conflito, das implicações e da arregimentação mobilizatória - como é percebida nos documentos analisados. Importante perceber também que um evento local/regional nos permite alçar compreensão de fenômenos mais amplos, como aspectos de uma época geológica.

É um processo que passa pela sensibilização, solidarização, validação e legitimação do sofrimento do outro distante. Nesse sentido, a construção argumentativa de Hans Joas (2013) sobre relação entre violência e dignidade humana aponta que experiências de impotência também nos moldam profundamente e que elas podem se transformar de tal maneira a gerar energia necessária para comprometimento com valores positivos (inclusive universais), como forças motivadoras.

Joas (2013) também se remete, ainda que com algumas ressalvas, às contribuições de Alexander (2012) quando fala do potencial do conceito de trauma para entender a gênese de valores. Em sua perspectiva, o sofrimento por si só não gera valores. São realmente necessárias narrativas para a construção de significado, sentido, de novos valores - a experiência de sofrimento precisa encontrar expressão em esquemas interpretativos, ela precisa de articulação - que o sofrimento seja dito e que pessoas os ouçam. E, de novo, ressurge a questão da seletividade: alguns eventos têm sido absorvidos na memória cultural coletiva em nível muito menor que outros. Alguns quesitos enumerados (JOAS, 2013) e que nos apropriamos ao lidar com condicionantes para o processo de trauma cultural tomar lugar: a sensibilidade ao sofrimento: ele nos toca? Por exemplo, os negacionistas blindam o acesso ao sofrimento ecológico, ou seja, existem também estratégias de dessensibilização; a possibilidade de revolta moral; o descentramento moral, ou seja, a capacidade de sentir a injúria moral do outro distante; as mudanças cognitivas (como a mudança, nos anos 1980, que os contagiados pelo HIV não eram 
monstros que deviam ser deixados morrer); o acesso às possibilidades de intervenção (jurídica, por exemplo, mas também quando grupos passam a ser capazes de elaborar e contar suas próprias histórias seja intelectualmente, literariamente, etc).

O que Hans Joas nos aponta em seu livro é um indicativo de como o sofrimento pode se tornar um vetor para a ação política, como ele pode ativar desejos amplos por justiça. Em Mariana, por exemplo, em uma unidade solidária e política, se juntam, conectados pelo teor da tragédia, outros atingidos por barragens, representados por entidades como o Movimento dos Atingidos por Barragens, agregando uma gramática particular de apelos.

Dessa forma, "é oportuno retomar a pedagogia em seu aspecto praxístico, meditando em seu uso estratégico-acional como condutor radical de e para compreensões do projeto decolonial, posturas e pensamentos não apenas críticos, mas de caráter imperativo" (WALSH, 2013, p.31) e nos perguntarmos que contribuições a leitura de ruínas de Mariana pode trazer para ler o mundo e intervir na reinvenção da sociedade (FREIRE, 1991) num mundo que "prega o fim do mundo como uma possibilidade de fazer a gente desistir dos nossos próprios sonhos" (KRENAK, 2019, p.27).

A ruína de Mariana também é palco de estratégias resistências, esperanças, articulações de solidariedade e formas de cuidado criativas, demandas políticas e de formas de vida e de valores que se esforçam em resistir e perseverar em um mundo quebrado (DAWNEY, 2020). Não é, nos cabe salientar, um lugar cristalizado pela destruição e abandono, uma relíquia perversa do Antropoceno.

\section{Considerações finais}

Tanto o estudo da AATR e o livro reportagem de mestrandos em Divulgação Científica e Cultural, da Universidade Estadual de Campinas se firmam nos relatos de sofrimento e de dano ambiental que norteiam nossa leitura de ruínas e sugerem apontamentos sobre o que significou a destruição em Mariana/MG. O primeiro documento foca na dimensão da justiça social não dissociada da justiça ecológica; o segundo convoca ainda especialistas e peritos, além dos atingidos, para montar um quadro de contextualização que tem como objetivo uma espécie de justiça narrativa, simbólica, bem como exercitam uma avaliação da cobertura da mídia 
tradicional - que conta com fotos, poemas, entrevistas e reportagens analíticas para atingir esse fim. Portanto, ambos os documentos realizam uma defesa dos atingidos (humanos e não-humanos), trazem para um primeiro plano os elementos sociais da catástrofe como a vulnerabilidade pré-existentes ao exibirem diferentes âmbitos da tragédia, valorizando e validando os relatos, das histórias de vida, versões e experiências dos atingidos.

O sofrimento dos atingidos, para os mestrandos (coautores do livroreportagem da Unicamp) e para os advogados e assessores jurídicos (escritores da sistematização sobre dano moral) acumula sentidos diversos, é lido com diferentes lentes: estes partem de uma ótica jurídica, que relaciona normas, doutrinas e realidade fática, para apontar cumprimentos ou descumprimentos da lei; os jornalistas fazem uma avaliação do que oficialmente se contou, tentam fazer uma modulação de narrativa. Ambos trabalham no estabelecimento, embora não o afirmem, do trauma cultural - sobretudo no que diz respeito ao descentramento moral, expansão de sensibilidade e ao cravarem o evento na memória pública em sua importância, pertinência e eloquência. Dito de outra forma, os documentos corroboram com a categoria trauma cultural ou viabilizam a leitura das ruínas catástrofe-crime em Mariana a partir da centralidade desse conceito.

Assim, fica explícito que a magnitude do dano depõe não apenas contra empresas mineradoras, não diz respeito apenas ao contexto regional ou circunscreve-se apenas aos atingidos - mas depõe contra todo o Antropoceno e a face sinistra de um modelo de desenvolvimento, um modelo de encarar os recursos naturais e de encarar o progresso. Investigações nesse nível tornarão mais evidentes ou mais nuançados esses elementos sociais ou essas externalidades sombrias do Antropoceno - como o trauma cultural. Ao prestar não apenas solidariedade, mas também auxiliar na articulação traumática do evento de Mariana, os documentos analisados explodem a fronteira ou os limites da experiência do atingido para que passe a significar um trauma cultural expandido para a comunidade mais ampla e, em nossa visão, contribuem para definir aquela catástrofe como um como marco do fim do mundo perpetrado pelo Capitaloceno/Necroneno.

\section{Referências}

ACOSTA, Alberto. Extraivismo e Neoextrativismo. In: DILGER, Gerhard (ORG). 
Descolonizar o Imaginário: debates sobre pós-extrativismo e alternativas ao desenvolvimento. São Paulo: Fundação Rosa Luxemburgo, 2016.

A SIRENE. Cerca de 900 dossiês entregues às famílias atingidas de Mariana. 2020. Disponível em: <http://jornalasirene.com.br/justica/2020/04/29/cerca-de-90o-dossiesentregues-as-familias-atingidas-de-mariana>. Acesso em: 02 jul 2020.

ALEXANDER, Jeffrey C. Trauma: A social theory. Cambridge: Polity, 2012.

ASSOCIAÇÃO DE ADVOGADOS DE TRABALHADORES RURAIS NO ESTADO DA BAHIA (AATR/BA). Estudo e sistematização dos danos morais individuais e coletivos para processo de indenização/reparação dos atingidos e atingidas pela barragem de rejeitos da Samarco (Vale e BHP Billiton) em Mariana-MG. Salvador: AATR/BA, 2018. Em fase de publicação.

BALLESTRIN, Luciana. América Latina e o giro decolonial. Revista Brasileira de Ciência Política, $\mathrm{n}^{\mathrm{o}} 11$. Brasília, maio - agosto de 2013, pp. 89-117. Disponível em: <https://www.scielo.br/pdf/rbcpol/n11/o4.pdf>. Acesso em 16 jul 2020.

BECK, Ulrich, GIDDENS, Anthony, LASH, Scott. Modernização Reflexiva. São Paulo: Unesp, 1997.

CALDAS, Graça (org). Vozes e silenciamentos em Mariana: crime ou desastre ambiental?. Campinas: BCCL/ UNICAMP, 2018. Disponível em: $<$ http://www.labjor.unicamp.br/wpcontent/uploads/2018/04/2a_edicao_digital_vozes_e_silenciamentos_em_Mari ana_06042018_LABJOR_09-04.pdf>. Acesso em 17 jul 2020.

CRUTZEN, Paul e STOERMER, Eugene. The Anthropocene. IGBP Newsletter, 41:17-18, 2000.

DAWNEY, Leila. Decommissioned places: Ruins, endurance and care at the end of the first nuclear age. Transactions of the Institute of British Geographers, 2020, v.45, n. $1 . \quad$ Disponível em: <https://rgsibg.onlinelibrary.wiley.com/journal/14755661>. Acesso em 16 jul 2020.

DÍAZ, Junot. Apocalypse. Boston Review. May 2011. Disponível em: < http://bostonreview.net/junot-diaz-apocalypse-haiti-earthquake >. Acesso em: 20 jun 2020.

FREIRE, Paulo. A Importância do Ato de Ler - em três artigos que se completam. São Paulo: Cortez Editora \& Autores Associados, 1991.

GOFFMAN, Erving. Estigmas: notas sobre a manipulação da identidade deteriorada. Tradução de Márcia Bandeira de Mello Leite Nunes. Rio de Janeiro: LTC, 2008.

HARAWAY, Donna. Anthropocene, Capitalocene, Chthulhucene. Donna Haraway in conversation with Martha Kenney. In: DAVIS, Heater; TURPIN, Etienne (org). Art in the Anthropocene: encounters among aesthetics, politics, environments 
and epistemologies. Open Humanities Press, 2015. Disponível em: http://www.openhumanitiespress.org/books/titles/art-in-the-anthropocene/>. Acesso em 17 jul 2020.

HEIDEGGER, Martin. A questão da técnica. In: HEIDEGGER, M. Ensaios e conferências. 8.ed. Petrópolis: Vozes, 2002. p. 11- 32.

HUI, Yuk. Cosmotechnics as Cosmopolitics. E-flux, no 86, November 2017. Disponível em: <https://www.e-flux.com/journal/86/161887/cosmotechnics-ascosmopolitics/>. Acesso em 17 jul 2020.

INSTITUTO BRASILEIRO DO MEIO AMBIENTE E DOS RECURSOS NATURAIS RENOVÁVEIS. Laudo Técnico Preliminar: Impactos ambientais decorrentes do desastre envolvendo o rompimento da barragem de Fundão, em Mariana, Minas Gerais, nov. 2015. Disponível em: <http://www.ibama.gov.br/phocadownload/barragemdefundao/laudos/laudo_te cnico_preliminar_Ibama.pdf >. Acesso em 17 jul 2020.

JOAS, Hans. A sacralidade da pessoa: nova genealogia dos direitos humanos. São Paulo: Editora Unesp, 2012.

KRENAK, Ailton. Ideias para adiar o fim do mundo. São Paulo: Companhia das Letras, 2019.

LANDER, Edgardo. La ciencia neoliberal. Revista Venezolana de Economía y Ciencias Sociales, Vol. 11, No. 2, Caracas, Universidad Central, mayo de 2005, 35-69. Disponível em: $<$ http://ve.scielo.org/scielo.php?script=sci_arttext\&pid=S1315-

$64112005000200003>$. Acesso em 16 jul 2020.

LATOUR, Bruno. Jamais fomos modernos: ensaio de antropologia simétrica. Rio de Janeiro: Editora 34, 1994.

MARQUES, Luiz. Capitalismo e colapso ambiental. $1^{\text {a }}$ ed. Campinas, SP: Editora da Unicamp, 2015.

MCBRIEN, J. Accumulating Extinction Planetary Catastrophism in the Necrocene. In: MOORE, J. (editor). Anthropocene or Capitalocene? Nature, History, and theCrisis of Capitalism. Oakland: PM Press, 2016.

MENEGAT, Marildo. A crítica do capitalismo em tempos de catástrofe: o giro dos ponteiros no pulso de um morto. Rio de Janeiro: Consequência, 2019.

MENEGAT, Marildo. Depois do fim do mundo: a crise da crise da modernidade e a barbárie. Rio de Janeiro: Relume Dumará; FAPERJ, 2003.

MiNistério PÚBliCo FEDERAL (MPF). Ação Civil Pública Samarco. Belo Horizonte. 2016. Disponível em: <http://www.mpf.mp.br/mg/sala-deimprensa/docs/acp-samarco >. Acesso em 02 jul 2020. 
MOORE, J. The Rise of Cheap Nature. MOORE, J. (editor). Anthropocene or Capitalocene? Nature, History, and the Crisis of Capitalism. Oakland: PM Press, 2016.

O TEMPO. Samarco perde no TJMG, e atingidos de Mariana podem definir valor de indenização. 2020. Disponível em: <https://www.otempo.com.br/economia/samarco-perde-no-tjmg-e-atingidos-demariana-podem-definir-valor-de-indenizacao-1.2296548>. Acesso em 2 jul 2020.

SANTOS, Antônio Bispo. Colonização, Quilombos, modos e Significações. Brasília: INCTI; UNB, 2015.

SEGATO, Rita Laura. Género y colonialidad: en busca de claves de lectura y de un vocabulario estratégico descolonial. In: BIDASECA, Karina Bidaseca; VAZQUEZ LABA, Vanesa Vazquez (comps.). Feminismos y poscolonialidad. Descolonizando el feminismo desde y en América Latina. Buenos Aires: Ediciones Godot, 2011, p.17-48. Disponível em:<https://nucleodegenerounr.files.wordpress.com/2013/o3/bidaseca-karinay-vazquez-laba-vanesa-comps-feminismos-y-poscolonialidad-descolonizando-elfeminismo-desde-y-en-amczagrica-latina.pdf> Acesso em 16 jun 2020.

SILVA, Gislene. Para pensar critérios de noticiabilidade. Revista Estudos em Jornalismo e Mídia, v.II, n.1, 2005. Disponível em: <https://periodicos.ufsc.br/index.php/jornalismo/article/view/2091>. Acesso em 29 jun 2020.

SIMANGAN, Dahlia. "Situating the Asia-Pacific in the Age of the Anthropocene." Australian Journal of International Affairs 73(6): 564-584, 2019. Disponível em: <https://www.tandfonline.com/doi/abs/10.1080/10357718.2019.1657794>.

Acesso em 28 Ago 2020.

UNICAMP. INSTITUTO DE ESTUDOS DA LINGUAGEM (IEL). Divulgação Científica e Cultural. Apresentação. s/a. Disponível em: $<$ https://www.iel.unicamp.br/br/content/divulga\%C3\%A7\%C3\%A30cient\%C3\%ADfica-e-cultural>. Acesso em 16 jul 2020.

UNICAMP. LABORATÓRIO DE ESTUDOS AVANÇADOS EM JORNALISMO (LABJOR). Mestrado Divulgação Científica e Cultural. s/a Disponível em: <http://www.labjor.unicamp.br/?page_id=233>. Acesso em 29 jun 2020.

VIGNOLO, Paolo. Notes for a minor Anthropocene. Azimuth, n. 9, 2017. Disponível em: <https://www.academia.edu/33230347/NOTES_FOR_A_MINOR_ANTHROPO CENE $>$. Acesso em 17 jul 2020.

WALSH, Catherine. Interculturalidad crítica/Pedagogía de-colonial. Revista de Educação Técnica e Tecnológica em Ciências Agrícolas, v.3, n.6, 2002. Disponível em: <http://www.ufrrj.br/SEER/index.php?journal=retta\&page=article\&op=downloa d\&path\%5B\%5D=1071\&path\%5B\%5D=1128>. Acesso em 16 jun 2020 
WALSH, Catherine. Lo pedagógico y lo decolonial: Entretejiendo caminos. In: WALSH, Catherine. Pedagogías decoloniales. Prácticas insurgentes de resistir, (re)existir y (re)vivir. Tomo I. Quito, Ecuador: Ediciones Abya-Yala, 2013, p.23-68

Recebido em: 19/11/2020. Aprovado em: 14/12/2020. Publicado em: 26/12/2020. 